\title{
DOSSIÊ: CONFLITOS, INJUSTIÇA, DESIGUALDADE E EDUCAÇÃO AMBIENTAL NA AMÉRICA LATINA
}

\author{
Adriana Paola Paredes Peñafiel; \\ Angel M. Segura \\ Caio Floriano dos Santos \\ Sérgio Botton Barcellos
}

Os conflitos socioambientais são processos correntes nas sociedades contemporâneas e têm gerado novos enfoques e abordagens sobre a questão ambiental. Não cabe dúvida que a região de América Latina continua sendo compreendida como um espaço de intervenção, para ser manipulada pelo conhecimento cientifico, subalternizando o conhecimento de coletivos a partir da experiência vivida. A diferença com relação a outras épocas é que atualmente as coalizões entre os Estados e as empresas conseguem identificar e estudar os impactos e justificam a inquestionabilidade das atividades de grande aporte de capital visto que os seus efeitos podem ser reduzidos a questões negociáveis com compensações econômicas despolitizando outras interpretações. Assim, aspectos que podem ser de natureza política devem ser "ajustados" a caracteres técnicos.

De outro lado, a organização de comunidades locais em colaboração com os ambientalistas, professores, entre outros que configuram os movimentos sociais, produzem conhecimento sobre o processo de usurpação dos seus mundos, sendo a maioria das vezes excluídas dos processos de tomada de decisão que envolvem os seus projetos de vida. A partir desse processo, elaboram-se pautas e reivindicações sociais e ambientais que têm fomentado outras formas de olhar para o conhecimento técnico-científico e para o atual estágio do desenvolvimento socioeconômico do capitalismo.

O modelo atual de uso e exploração aos bens naturais produz desigualdades sociais e ambientais que atingem de maneira desproporcional os diferentes grupos sociais (ACSELRAD, 2010; PORTO e PACHECO, 2009). Os conflitos socioambientais derivam das disputas entre os diferentes grupos humanos pelo acesso aos bens naturais desenhados na natureza. Entretanto, 
o que Blaser (2013) e outros autores têm mostrado é como outras realidades (naturezas) se tornam visíveis, desafiando o relativismo cultural, onde não existe uma divisão entre cultura/natureza ou indivíduo/comunidade, mas uma contínua relação para a produção da vida.

Os conflitos também abrem a possibilidade de se perceber que alguns grupos sociais são cometidos de modo mais severo pela implementação de projetos industriais, econômicos e ambientais. Inclusive, sendo culpados e insultados por entorpecer os projetos de desenvolvimento. Essas relações, muitas vezes antagônicas, envolvem desde questões referentes à exploração direta dos bens (solo, água, minérios etc.) até as relações de território e territorialidade.

No que tange ao aspecto socioambiental, Acselrad (2004) descreveu que dois processos caracterizaram a territorialidade do capitalismo brasileiro, sendo que o primeiro diz respeito à concentração crescente do controle dos bens naturais por poucos atores e a acumulação capitalista, que faz uso de escalas cada vez mais amplas de produção, de avanços sobre novos espaços sociais para a exploração do trabalho e de especulação fundiária. O segundo processo na construção desta territorialidade foi à privatização do uso de espaços de uso comum com a reprodução de um modelo da sociedade capitalista moderna e com a intensificação da produção do trabalho no ambiente. Para além do contexto brasileiro, essa dinâmica do capitalismo nos remete a refletir sobre a América Latina e diversos territórios no mundo. Isso significa compreender a unidade entre as relações sociais inerentes à natureza - história - sociedade.

A esse respeito, o conceito de "colonialidade" de Aníbal Quijano (2007) parece pertinente. Uma característica central dela é a classificação hierárquica das diferenças que leva à supressão, desvalorização, subordinação, e inclusive destruição de formas de conhecimentos para a emergência e constituição do capitalismo. Esta estrutura de classificação até os dias de hoje indica quem deve ser "sacrificado" e "quem não" no sistema-mundo capitalista.

Sob essa perspectiva, a educação ambiental vem sendo acionada, a partir de uma lente crítica e emancipadora, para refletir sobre respostas para algumas questões que se tornam cada vez mais candentes em um mundo com diversos conflitos socioambientais em diferentes níveis. Estes conflitos mobilizam e impactam povos e comunidades tradicionais (áreas indígenas, 
quilombolas, comunidades ribeirinhas, pescadores, caiçaras, etc), agricultores familiares, pescadores artesanais, povos das florestas, até o sistema financeiro, as grandes corporações industriais, comerciais e os Estados com seus Grandes Projetos de Desenvolvimento (GPD's) no Brasil e América Latina.

No Brasil temos diversos conflitos envolvendo a disputa pela terra com famílias e povos indígenas com casos de homicídio, denúncias constantes de infrações ambientais cometidas por empresas do agronegócio e de mineração. Exemplo disso, além de uma das maiores catástrofes ambientais da nossa história com o rompimento da barragem da Samarco em Rio Doce em Minas Gerais, com as recentes contaminação do Rio Pará em Barcarena e o rompimento de minerodutos da Anglo American em Minas Gerais. Além disso, o número de assassinatos no campo brasileiro atingiu o maior número desde 2003, alcançando70 assassinatos (CPT, 2018). Destaca-se que de acordo com Mapa de Conflitos envolvendo Injustiça Ambiental e Saúde no Brasil, até agosto de 2016 haviam 571 conflitos socioambientais registrados no Brasil na sua maioria ocasionados por conflitos fundiários e por contaminação de rios e mananciais hídricos. No que tange as populações acometidas por estes conflitos, $33 \%$ atingem agricultores familiares e $28 \%$ indígenas. Destaca-se também que $22 \%$ desses conflitos impactam comunidades quilombolas.

Diante desse conjunto de aspectos e acontecimentos, um Dossiê em uma Revista Acadêmica é pertinente para retratar as diversas configurações dos conflitos socioambientais no Brasil e na América Latina tendo como pano de fundo a disputa por diferentes perspectivas de natureza, território e bens naturais.

Sob essa perspectiva, o Dossiê "Dossiê: Conflitos; Injustiça, desigualdade e educação ambiental na América Latina" conta com a participação de doze pesquisadores (as) de diversas universidades do Brasil com seis artigos que abordam diferentes temáticas e objetos de pesquisa sobre a questão socioambiental.

Inicialmente, no artigo "Travessias para educação ambiental 'desde el sur': uma agenda política critica comum em 'zonas de sacrifício' como o Brasil e América Latina" Patricia de Oliveira Plácido, Elza Maria Neffa Vieira de Castro e Mauro Guimarães abordam os conflitos ambientais em 'zonas de sacrifício' discutem a educação ambiental sob uma perspectiva epistemológica 
freireana e do "ecologismo dos pobres" apoiados na Ecologia Política. A partir dessa perspectiva, as autoras e o autor trazem algumas possibilidades para pensar qual agenda política pode ser comum em práticas de educação ambiental 'desde del Sur' que se propõe ao enfrentamento das desigualdades contidas em zonas de sacrifício ambiental.

Tatiana Walter, Liandra Peres Caldasso, Jéssica Fischer e Ivanilda Foster Almeida discutem no artigo "Por uma racionalidade ambiental: reflexões acerca dos regramentos propostos para a pesca da tainha no estuário da Lagoa dos Patos/RS" como o Estado - com apoio do discurso científico realiza regulações ambientais considerando apenas uma relação dicotômica entre sociedade ambiente. Ao analisarem as normativas em vigor as autoras se deparam com uma visão biologicista e estado-centrada, que acabam por inviabilizar a pesca artesanal no Estuário da Lagoa dos Patos e acabam por dar sustentação a pesca industrial.

No artigo intitulado "Povos tradicionais caiçaras, educação escolar e justiça ambiental na Península da Juatinga, Paraty-RJ" Vanessa Marcondes de Souza e Carlos Frederico Bernardo Loureiro discutem as formas de que diante do enfrentamento de diversos processos de expropriação, os povos tradicionais caiçaras da Península da Juatinga, Paraty-RJ, passaram a demandar o acesso à educação escolar. Ela e ele abordam os elementos que conjuntamente produzem situações de injustiça ambiental e os processos de expropriações desses povos com foco no papel da educação escolar neste processo. Destacam, a partir desse trabalho, como a luta pela educação escolar desses povos, como parte constitutiva de suas lutas pelo direito de reproduzirem seus modos de vida, está inserida no contexto de resistência e enfrentamento à dominação social e à injustiça ambiental.

"Sobre o que cantam as mulheres camponesas e ronderas de Cajamarca?" é o título do artigo de autoria de Adriana Paola Paredes Penafiel analisa as manifestações de mulheres camponesas e ronderas de Cajamarca (Peru) em forma de cantos sobre a resistência contra o projeto de mineração Conga em espaços de diálogos com diversas audiências simpatizantes da luta. Estes cantos tornam visíveis relações e protocolos com a água e com a terra e restituem a autoridade às relações que permitem a continuidade da vida como uma prática cosmopolítica insurgente que torna visíveis os "seres da terra" sob os efeitos da mineração. Os encontros entre estas mulheres e as várias 
audiências são espaços para estender conhecimentos, sobre as práticas, pensares, entre pessoas de regimes de relação diferentes para uma proposta cosmopolítica.

Tauan Sousa, Horácio Antunes de Sant'Ana Júnior abordam em "Educação ambiental crítica ou conservadora? elementos para uma reflexão crítica acerca do projeto Ecoa" um projeto de Educação Ambiental realizado por um empreendimento siderúrgico na Zona Rural do município de São LuísMA no âmbito dos marcos teóricos da Educação Ambiental contemporânea, isto é, dentre o debate de uma educação conservadora ou educação ambiental crítica. Na pesquisa a autora e o autor concluem que o projeto analisado compõe o primeiro grupo e, dentro do quadro de conflitos ambientais existentes nesta região, não contribui para o fortalecimento do processo de resistência das populações locais.

Por fim, Carla Manoela Costa Rodrigues e Marcelo Campêlo Dantas problematizam no trabalho "A Perspectiva discente sobre os resíduos sólidos em uma escola do semiárido nordestino" a percepção dos estudantes de uma escola da rede pública de ensino sobre os resíduos sólidos no âmbito da educação ambiental. Apesar dos discentes conheceram certas condutas sustentáveis, ainda não estão a par da realidade social caracterizada pela produção de lixo. Desse modo, no estudo a autora e o autor perceberam que os projetos e ações governamentais são os meios mais referidos na conscientização e que uma possível minimização do lixo pode ocorrer por meio de ações sustentáveis de acordo com os estudantes que participaram da pesquisa.

Os trabalhos deste dossiê apresentam diferentes perspectivas teóricometodológicas em educação ambiental e esperamos, por meio das suas respectivas leituras e repercussões, que possam ser mais uma ferramenta para suscitar debates públicos. É com satisfação que publicamos esse conjunto de trabalhos e pesquisas na Revista Ambiente \& Educação do Programa de PósGraduação em Educação Ambiental (PPGEA) da Universidade Federal do Rio Grande (FURG), em seu primeiro número de 2018.

Desejamos a todos (as) uma ótima leitura e reflexão!

\section{REFERÊNCIAS BIBLIOGRÁFICAS}

ACSELRAD. H. Ambientalização das lutas sociais. Revista Estudos Avançados, v. 24, n. 68, p. 103-119, 2010. 
ACSELRAD, $\mathrm{H}$. As práticas espaciais e o campo dos conflitos ambientais. In: ACSELRAD, H. (Org.). Saúde Soc. São Paulo, v.24, n.4, p.1208-1216. Conflitos ambientais no Brasil. Rio de Janeiro: Relume-Dumará: Fundação Heinrich Böll, 2004.

BLASER, M. Ontological conflicts and the stories of peoples in spite of Europe. Current Anthropology, Chicago, v. 54, n. 5, p. 547-568, 2013. .

PORTO, M. F. S.; PACHECO, T. Conflitos e injustiça ambiental em saúde no Brasil. Tempus Acta em Saúde Coletiva, Brasília, DF, v. 4, n. 4, p. 26-37, 2009.

QUIJANO, A. Colonialidad del Poder, Cultura y Conocimiento en América Latina. Anuário Mariateguiano, Lima, v. 9, n. 9, 1997. 